\title{
Primary T-cells from human CD4/CCR5-transgenic rats support all early steps of HIV-I replication including integration, but display impaired viral gene expression Christine Goffinet $^{1}$, Nico Michel ${ }^{1}$, Ina Allespach ${ }^{1}$, Hanna-Mari Tervo ${ }^{1}$, Volker Hermann1 ${ }^{1}$, Hans-Georg Kräusslich1, Warner C Greene ${ }^{2,3}$ and Oliver T Keppler*1
}

Address: ${ }^{1}$ Department of Virology, University of Heidelberg, Heidelberg, Germany, ${ }^{2}$ Gladstone Institute of Virology and Immunology, San Francisco, USA and ${ }^{3}$ Departments of Medicine and Microbiology and Immunology, University of California San Francisco, San Francisco, USA

Email: Christine Goffinet - Christine.goffinet@med.uni-heidelberg.de; Nico Michel - nico.michel@med.uni-heidelberg.de; Ina Allespach - ina.allespach@med.uni-heidelberg.de; Hanna-Mari Tervo - hanna-mari.tervo@med.uni-heidelberg.de; Volker Hermann - Volker.Hermann@web.de; Hans-Georg Kräusslich - hans-georg.kraeusslich@med.uni-heidelberg.de; Warner C Greene - wgreene@gladstone.ucsf.edu; Oliver T Keppler* - oliver_keppler@med.uni-heidelberg.de

* Corresponding author

Published: 26 July 2007

Retrovirology 2007, 4:53 doi:10.1 186/1742-4690-4-53

This article is available from: http://www.retrovirology.com/content/4/I/53

(C) 2007 Goffinet et al; licensee BioMed Central Ltd.

This is an Open Access article distributed under the terms of the Creative Commons Attribution License (http://creativecommons.org/licenses/by/2.0), which permits unrestricted use, distribution, and reproduction in any medium, provided the original work is properly cited.

\begin{abstract}
Background: In vivo studies on HIV-I pathogenesis and testing of antiviral strategies have been hampered by the lack of an immunocompetent small animal model that is highly susceptible to HIV-I infection. Since native rodents are nonpermissive, we developed transgenic rats that selectively express the HIV-I receptor complex, hCD4 and hCCR5, on relevant target cells. These animals display a transient low-level plasma viremia after $\mathrm{HIV}-\mathrm{I}_{\mathrm{YU}-2}$ infection, demonstrating HIV-I susceptibility in vivo. However, unlike macrophages, primary CD4 T-cells from double-transgenic animals fail to support viral spread ex vivo. To identify quantitative limitations or absolute blocks in this rodent species, we quantitatively assessed the efficiency of key steps in the early phase of the viral replication cycle in a side-by-side comparison in infected cell lines and primary T-cells from hCD4/hCCR5-transgenic rats and human donors.
\end{abstract}

Results: Levels of virus entry, HIV-I cDNA synthesis, nuclear import, and integration into the host genome were shown to be remarkably similar in cell lines and, where technically accessible, in primary T-cells from both species. In contrast, a profound impairment at the level of early HIV gene expression was disclosed at the single-cell level in primary rat Tcells and most other rat-derived cells. Macrophages were a notable exception, possibly reflecting the unique transcriptional milieu in this evolutionarily conserved target cell of all lentiviruses. Importantly, transient transcomplementation by ex vivo nucleofection with the Tat-interacting protein Cyclin TI of human origin markedly elevated HIV gene expression in primary rat T-cells.

Conclusion: This is the first study that has quantitatively determined the efficiency of consecutive steps in the HIV-I replication cycle in infected primary HIV target cells from a candidate transgenic small animal and compared it to human cells. Unlike cells derived from mice or rabbits, rat cells complete all of the early steps in the HIV-I replication cycle, including provirus integration in vivo, with high efficiency. A deficiency in gene expression was disclosed at the single cell level and could be counteracted by the human PTEFb transcription complex factor Cyclin TI. Collectively, these results provide the basis for the advancement of this transgenic rat model through strategies aimed at boosting HIV-I gene expression in primary rat CD4 T-cells, including human Cyclin TI transgenesis. 


\section{Background}

A highly HIV-permissive rodent with an intact and welldefined immune system would be a boon for the study of HIV pathogenesis and the rapid preclinical evaluation of antiviral strategies. However, native mice and rats cannot be infected by HIV. Species-specific barriers restricting HIV-1 replication in rodents manifest themselves at various steps of the viral replication cycle. Over the past decade, much has been learned about the complex interplay of virus and host, and this work has resulted in a greater molecular understanding of these restrictions in cell lines derived from candidate species, including mice, rats, rabbits, and hamsters. The first important advance was an appreciation of human chemokine receptors, most notably human CCR5 (hCCR5) and CXCR4 (hCXCR4), as cofactors with human CD4 (hCD4) for efficient binding, fusion, and entry of HIV-1 (reviewed in [1]). Indeed, coexpression of hCD4 and hCCR5 or hCXCR4 in cell lines from several small animals [2-9] or in transgenic mice and rats [10-12] is necessary and sufficient for HIV-1 entry, albeit at efficiencies which were suggested to be low $[7,9]$.

More recently, early HIV-1 post-entry barriers have been described in an adherent rabbit cell line [13] and cultured mouse T-cells $[5,14]$, the molecular basis of which has not been defined. Also, efficient Tat-dependent viral gene expression from the HIV-1 long terminal repeat (LTR) occurred in cell lines from mice and hamsters only in the presence of Cyclin T1 of human origin [15]. Orthologues from mouse and hamster, in association with cyclindependent kinase CDK9, cannot bind the TAR stem-loop near the 5'-end of nascent HIV-1 transcripts. Efficient HIV1 transcript elongation by the cellular RNA polymerase II depends on this critical process $[16,17]$. Interestingly in this context, previous reports suggested considerably higher levels of HIV gene expression in infected, ratderived Rat 2 cells compared to mouse NIH-3T3 and hamster CHO cells, even in the absence of human Cyclin T1 expression $[4,7,9]$.

Additional downstream barriers in rodent cells may limit the production of infectious virus [18]. Specifically, the function of HIV-1 Rev in regulating the splicing and nuclear export of viral transcripts [7,9,19] seems impaired. Moreover, a recessive defect at the level of HIV1 assembly $[7,20]$ and a maturation or APOBEC3Gdependent infectivity defect $[9,21]$ have been proposed in certain mouse and hamster cell lines, although their severity is still controversial $[4,7,9,11]$.

In contrast, certain rat cell lines co-expressing hCD4 and hCCR5 supported a full HIV-1 replication cycle and the release of infectious virions, although virus production in a single replication cycle was still less than $10 \%$ of that in human reference cultures [4]. Thus, the major block to
HIV-1 infection in rat cells appeared to be at the level of cellular entry and could be overcome by expression of the HIV-1 receptor complex. Based on these findings, immunocompetent Sprague-Dawley rats were generated that transgenically express hCD4 and hCCR5 selectively on CD4 T-cells, macrophages, and microglia [11]. After systemic challenge with the R5 HIV-1 strain YU-2 (HIV-1 1 YU${ }_{2}$ ), these double-transgenic rats harbored significant levels of episomal HIV-1 cDNA species in lymphatic organs and displayed a low-level plasma viremia up to 7 weeks postchallenge, demonstrating susceptibility to HIV-1 in vivo [11]. Furthermore, a recent proof-of-principle study highlighted the utility of these double-transgenic rats for a rapid preclinical evaluation of the inhibitory potency and of the pharmacokinetic properties of antiviral compounds targeting HIV entry or reverse transcription [22].

Although promising, the model still has limitations: levels of plasma viremia were modest and not sustained. This may be due to a cell type-specific block to productive HIV1 infection in double-transgenic rats. Primary rat macrophages and microglia, but not cultures from T-lymphocytes, could be productively infected by recombinant and primary R5 HIV-1 strains [11]. This barrier to HIV-1 replication in primary rat $\mathrm{CD} 4$ T-cells apparently prevented this important cell population from contributing to the viral load in vivo and further manipulations of this rodent model may be required to achieve high-level permissivity.

To gain insight into the nature and magnitude of the limitation, the current study focused on a quantitative sideby-side assessment of early steps in the HIV-1 replication cycle in infected primary T-cells from hCD4/hCCR5-transgenic rats and humans. In principle, the exclusive analysis of one HIV cDNA species or gene product would solely reflect a "cumulative" efficiency of all preceding steps and may completely mask severe quantitative deviations, be it higher or lower, in the efficiency of individual steps in the rat-human species comparison. For example, a 10-fold enhancement at the level of HIV entry in hCD4/hCCR5transgenic rat T-cells could potentially compensate a 10fold reduction at the level of reverse transcription, resulting in comparable levels of preintegration complexes for subsequent nuclear import and integration. Knowledge on the efficiency of individual steps in the HIV life cycle is thus pertinent for the validation of this HIV-susceptible small animal model and provides the basis for the interpretation and predictive value of in vivo infection studies. Consequently, the efficiencies of virion fusion, reverse transcription and nuclear import, provirus formation, and early viral gene expression were analyzed to pinpoint quantitative limitations or absolute blocks in the early phase of replication. 


\section{Results \\ Primary T-cells from hCD4/hCCR5-transgenic rats support a productive infection by MoMLV, but not by HIV-I, in ex vivo cultures}

We first investigated the ability of HIV-1 to productively infect and spread in primary rat T-cells that transgenically express the HIV-1 receptor complex. Spleen-derived Tcells from a hCD4/hCCR5-transgenic or from a hCD4transgenic control rat, or T-cells derived from human peripheral blood were infected with $\mathrm{HIV}-1_{\mathrm{YU}-2}$, and the infection kinetics were followed by monitoring p24 CA concentrations in culture supernatants. As expected, activated human T-cells showed a productive and AZT-sensitive infection (Fig. 1A). In contrast, supernatants from HIV-1 $1_{\mathrm{YU}-2}$-exposed rat T-cell cultures contained only background levels of p24 CA that did not increase over time (Fig. 1A).

To exclude the presence of a broad-spectrum anti-retroviral activity in these rat $\mathrm{T}$-cell cultures, we challenged them in parallel with a replication-competent ecotropic Moloney murine leukemia virus carrying an IRES-egfp element in the untranslated region between env and the 3'-LTR (MoMLV-GFP). Rat T-cell cultures were highly susceptible to MoMLV-GFP infection, reflected by rapidly increasing percentages of GFP-positive T-cells (Fig. 1B). Conversely, human T-cells did not support a MoMLV-GFP infection,

A

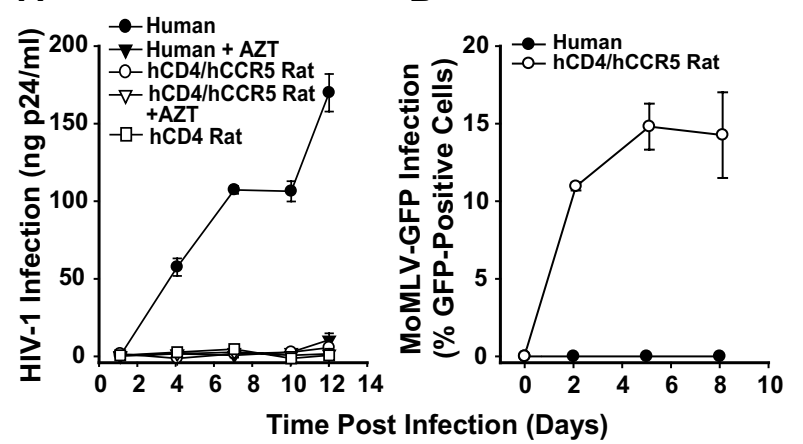

Figure I

HIV-I, in contrast to MoMLV, does not spread in primary T-cells from hCD4/hCCR5-transgenic rats. (A) Activated primary T-lymphocytes from a human donor, a hCD4/hCCR5-transgenic, or a hCD4-single-transgenic rat were infected with HIV-I ${ }_{Y U-2}\left(5\right.$ ng P24 CA per 2-3 × $10^{6}$ cells) overnight and washed. Culture supernatants were monitored for the presence of p24 CA. Where indicated, cultures were treated with AZT (10 $\mu \mathrm{M})$. (B) The same cultures were exposed to replication-competent ecotropic MoMLV-GFP. Percentages of GFP-positive, productively infected cells were determined by flow cytometry. All values are the arithmetic mean \pm S.D. of triplicates. Data are representative for two independent experiments. due to the absence of murine cationic amino acid transporter-1, the rodent-specific entry receptor for ecotropic MoMLV [23].

Thus, primary rat T-cells, despite expression of the HIV-1 receptor complex, fail to support a productive and spreading HIV-1 infection, but are highly permissive for infection by a mammalian gamma-retrovirus and thus do not impose a general restriction to retroviral infection.

\section{HIV-I efficiently enters primary T-cells from hCD4I hCCR5-transgenic rats}

We quantitatively analyzed each early step in the HIV-1 replication cycle with human $\mathrm{T}$-cells serving as a reference. First, the efficiency of HIV-1 entry was assessed in a flow cytometry-based virion-fusion assay [24,25]. T-cells from both species, activated for 5-10 days, were challenged with $\mathrm{HIV}-1_{\mathrm{YU}-2}$ virions carrying BlaM-Vpr. The cell-permeable CCF2 substrate was introduced into the target cells. After virion fusion, BlaM-Vpr cleaves CCF2, and the altered fluorescence emission serves as a sensitive and specific marker for viral entry. Notably, cell-surface levels of hCD4 were similar, but levels of hCCR5 were markedly higher on CD4 T-cells from transgenic rats than on those from their human counterparts ([11] and data not shown).

The percentages of T-cells from hCD4/hCCR5-transgenic rats and humans that allowed $\mathrm{HIV}-1_{\mathrm{YU}-2}$ entry was statistically indistinguishable $(1.2 \pm 1.0 \%$ and $1.4 \pm 1.3 \%$, respectively; $\mathrm{p}=0.66$; n.s.; Mann-Whitney $U$ test) (Fig. $2 \mathrm{~A}$ and $2 \mathrm{~B}$ ). Mock-infected T-cells or T-cells that had been treated either with the fusion inhibitor enfuvirtide (T20) or with the CCR5 antagonist TAK-779 before exposure to the cell-free viral inoculum (50 ng p24 CA) displayed only background levels of cleaved CCF2-positive cells (Fig. 2A and 2B). As an additional control of specificity, the CXCR4 antagonist AMD3100 did not significantly ( $\mathrm{p}=$ 0.9 (human); $\mathrm{p}=0.2$ (rat)) affect the ability of the R5 HIV1 strain to fuse with these primary T-cells.

To explore species-specific differences in the relationship between the dose of inoculum and the efficiency of virion fusion, primary T-cells were exposed to increasing doses of HIV-1 ${ }_{\mathrm{R} 7 / 3}$ YU-2 Env GFP carrying BlaM-Vpr (Fig. 2C, the presence of the GFP gene is unimportant in this assay). In a titration of the inoculum covering three orders of magnitude, T-cells from hCD4/hCCR5-transgenic rats supported HIV-1 entry at levels that closely matched those of their human counterparts (Fig. 2C). Human T-cells, which had been pretreated with an anti-CCR5 antibody, and Tcells from a hCD4-transgenic rat served as controls and were largely refractory to virion fusion. In summary, these results show that expression of the HIV-1 receptor complex on primary rat T-cells efficiently overcomes the HIV- 

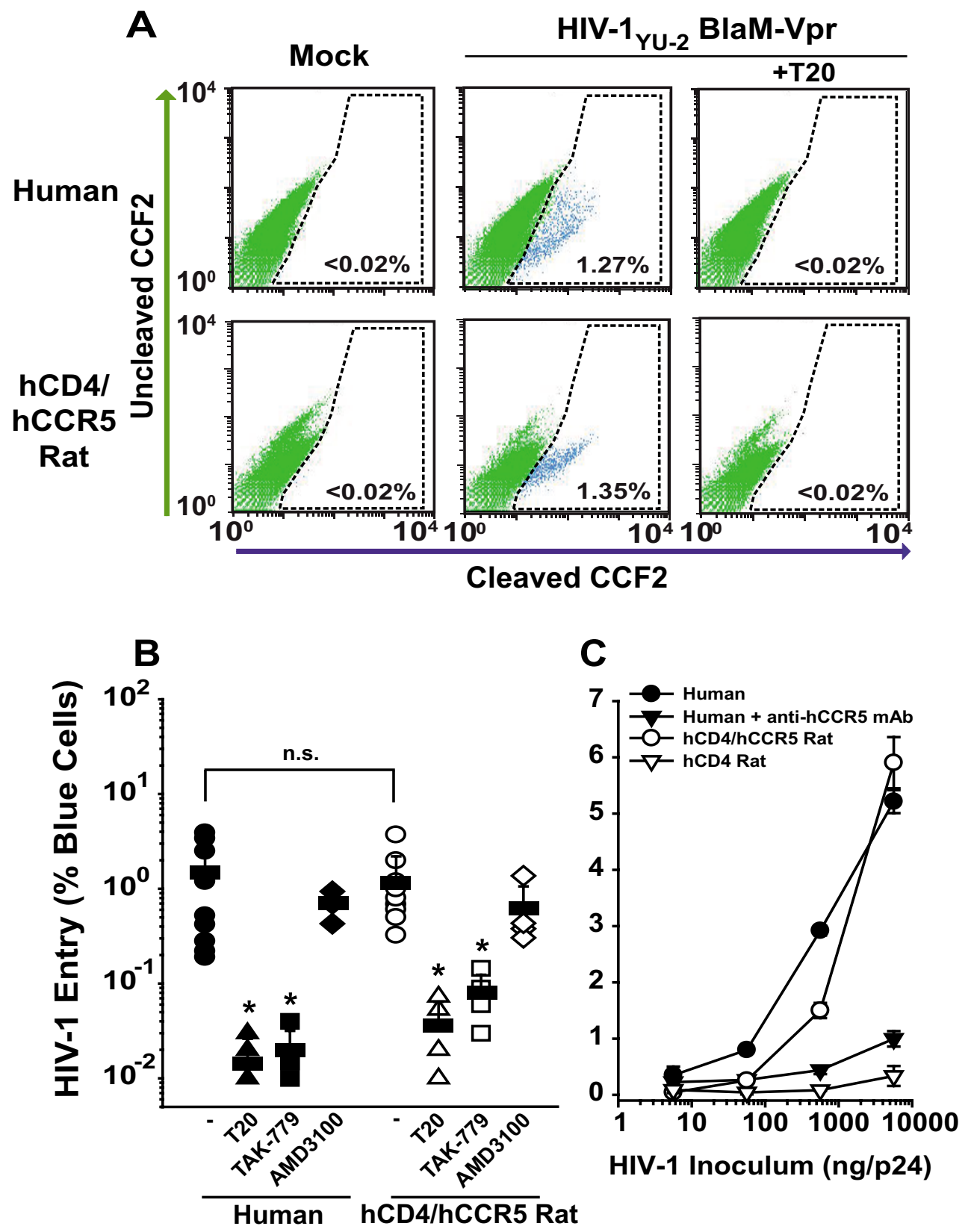

Figure 2

Transgenic expression of hCD4 and hCCR5 efficiently overcomes the HIV-I entry block in primary rat T-lym-

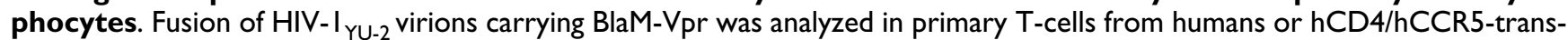
genic rats by multi-parameter flow cytometry [22,25]. (A) Representative FACS dot plots for the detection of cleaved CCF2 substrate, reflecting HIV-I entry. T-cells from humans (upper panels) and double-transgenic rats (lower panels) were either mock-infected (left panels) or infected with HIV-I YU-2 $\left(50\right.$ ng HIV-I p24 CA per 2-3 $\times 10^{6}$ cells), either without (middle panels) or with (right panels) the fusion inhibitor T20 (50 $\mu \mathrm{M})$. (B) Results from virion-fusion assays with T-cells from 5-9 different donors per species. Were indicated, the CCR5 antagonist TAK-779, the CXCR4 antagonist AMD3 I00 (both I $\mu$ M), or T20 $(50 \mu \mathrm{M})$ were added I5-30 min before virus challenge. Symbols indicate arithmetic means of triplicates from one virion-fusion experiment; horizontal bars depict the arithmetic mean \pm S.E.M. of all experiments (n.s. $=$ not significant; $p=0.66 ; * p \leq 0.02$ ) (C) Titration of HIV-I $\mathrm{R}_{\mathrm{R} / 3}$ YU-2 Env GFP carrying BlaM-Vpr in virion-fusion assays on primary T-cells from both species. Where indicated (filled triangle) the anti-hCCR5 mAb 2D7 $(50 \mu \mathrm{g} / \mathrm{ml})$ were added to cells 15-30 min before virus challenge. 
1 entry block. This suggests that limitations further downstream in the replication cycle restrict productive infection in these rodent cells.

\section{Nuclear import of de novo synthesized viral DNA genomes is similar in primary $T$-cells from rats and humans}

Next, we determined if the HIV-1 replication defect in primary rat T-cells could be accounted for by a reduced efficiency of reverse transcription or nuclear import of newly synthesized HIV-1 CDNA, as suggested for mouse T-cells $[5,14]$. To ensure comparable conditions in the cross-species comparisons, infections were genetically limited to a single round. As a consequence, the absolute levels of individual processes in this primary cell type were generally low. Infections were conducted with HIV-1 generated from a replication-deficient HIV-1 $1_{\mathrm{NL4}-3} \mathrm{E}-\mathrm{GFP}$ backbone pseudotyped with YU-2 Env. This approach allowed a kinetic analysis of the formation of HIV-1 2-LTR circles. 2LTR circles are an episomal HIV cDNA species, are formed exclusively in the nucleus by cellular ligases of the nonhomologous DNA end joining pathway [26], and serve as a quantitative marker for reverse transcription and nuclear import of the viral cDNA genome [27].

2-LTR circles were detected in infected primary T-cells from both species, and peak levels differed by no more than twofold (Fig. 3). In contrast, no 2-LTR circles could be detected in efavirenz-treated cultures or cultures from a hCD4-single-transgenic rat, demonstrating that the amplified episomal HIV-1 cDNAs had been generated de novo after a receptor-complex-mediated infection and were not present in the inoculum. Furthermore, flow cytometric analysis $96 \mathrm{~h}$ after infection showed similar percentages of T-cells expressing GFP from the nef locus (0.70.9\% GFP-positive cells, Fig. 3) for infected cultures from both species, and DNA extracts from samples taken at the same time point contained comparable levels of 2-LTR circles (0.53-0.81 copies per ng of DNA; Fig. 3). Thus, infected primary rat T-cells appear to support reverse transcription and nuclear import of de novo synthesized HIV1 cDNA at levels similar to human reference cells, and early HIV gene products can be expressed. These results suggest that limitations underlying the replication block in infected T-cells from this rodent species must be acting at a step after nuclear entry of the preintegration complex.

A quantitative nested PCR to detect integrated HIV-I DNA in rat cells

To assess the next major step in the HIV-1 replication cycle, we quantified provirus formation in infected rat cells. In principle, a defect at the level of integration can completely abrogate HIV-1 replication, but may still allow expression of early viral proteins, including Nef, from episomes in the first round of infection $[28,29]$.

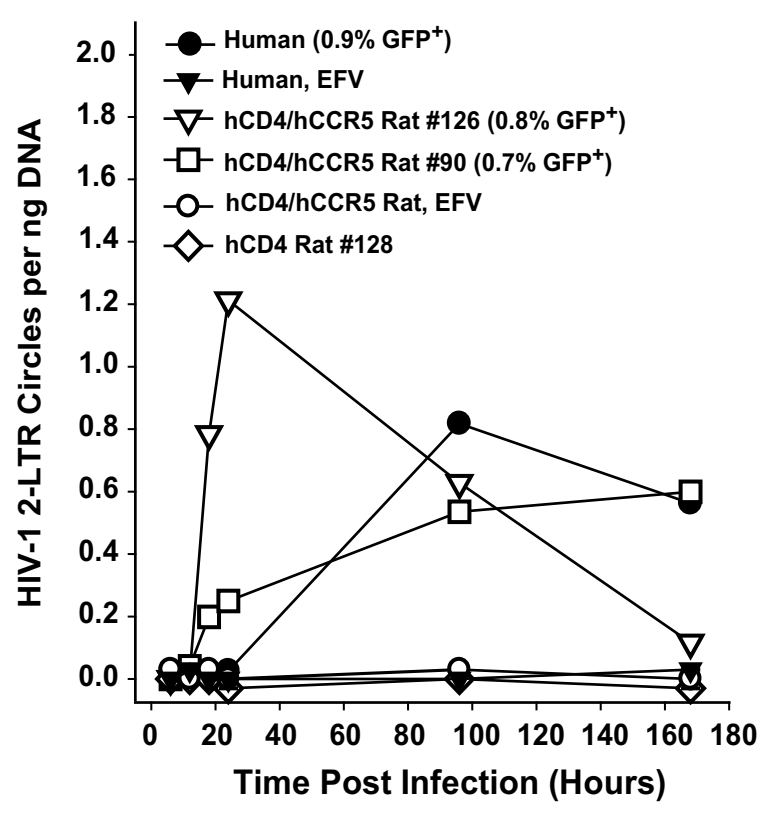

Figure 3

Reverse transcription and nuclear import of de novo synthesized HIV-I cDNA are well supported in Tcells from hCD4/hCCR5-transgenic rats. Primary Tcells from a human donor or from transgenic rats were exposed to YU-2 Env pseudotyped HIV-I ${ }_{\mathrm{NL} 4-3} \mathrm{E}_{-}$GFP. At the indicated time points, post-infection samples were taken from cultures, and the relative levels of 2-LTR circles in cell extracts were scored by quantitative PCR. The percentage of GFP-positive cells at day $\mathbf{4}$ after infection is given in parentheses.

Similar to a reported nested PCR strategy to specifically amplify HIV-1 integrated in proximity to genomic Alu repeat elements in human cells [30], we designed a nested real-time PCR assay to detect integrated HIV-1 provirus in rat cells by employing an ID consensus sequence within the rat BC1 RNA gene $[31,32]$ as the rodent repeat target for the cellular anchor primer pair. To serve as standards for species-specific quantitative analyses of provirus formation, stable populations of human and rat cell lines containing integrated HIV-1 proviruses were generated (Fig. 4A): adherent HeLa (human) and Rat2 (rat) cells were infected with VSV-G pseudotyped HIV-1 $1_{\mathrm{NL4}-3} \mathrm{E}^{-} \mathrm{GFP}$ at a low multiplicity of infection and subsequently passaged for 7 weeks to allow complete loss of unintegrated HIV-1 cDNA species. After an overnight-stimulation with the histone deacetylase inhibitor trichostatin A, GFPexpressing cells were enriched by flow cytometric sorting, and bulk cultures of these provirus-containing, heterogeneous cell populations, named HeLaint and Rat $2^{\text {int, }}$ were expanded. Since these cells no longer contain unintegrated HIV-1 cDNA species, the absolute number of integrated proviruses per ng cellular DNA in HeLaint and 
A
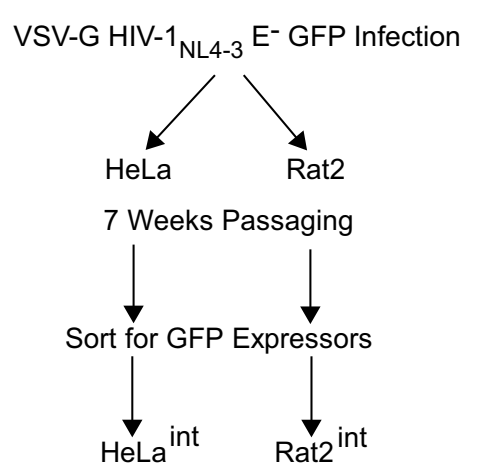

B

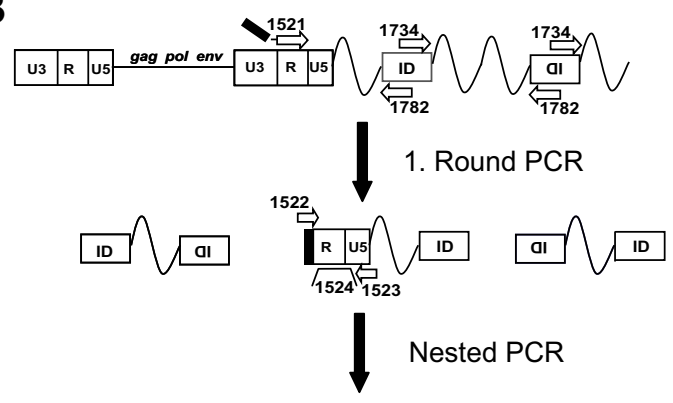

R日us R⿴囗十

\begin{tabular}{|l|l|}
\hline$R$ & U5 \\
\hline
\end{tabular}

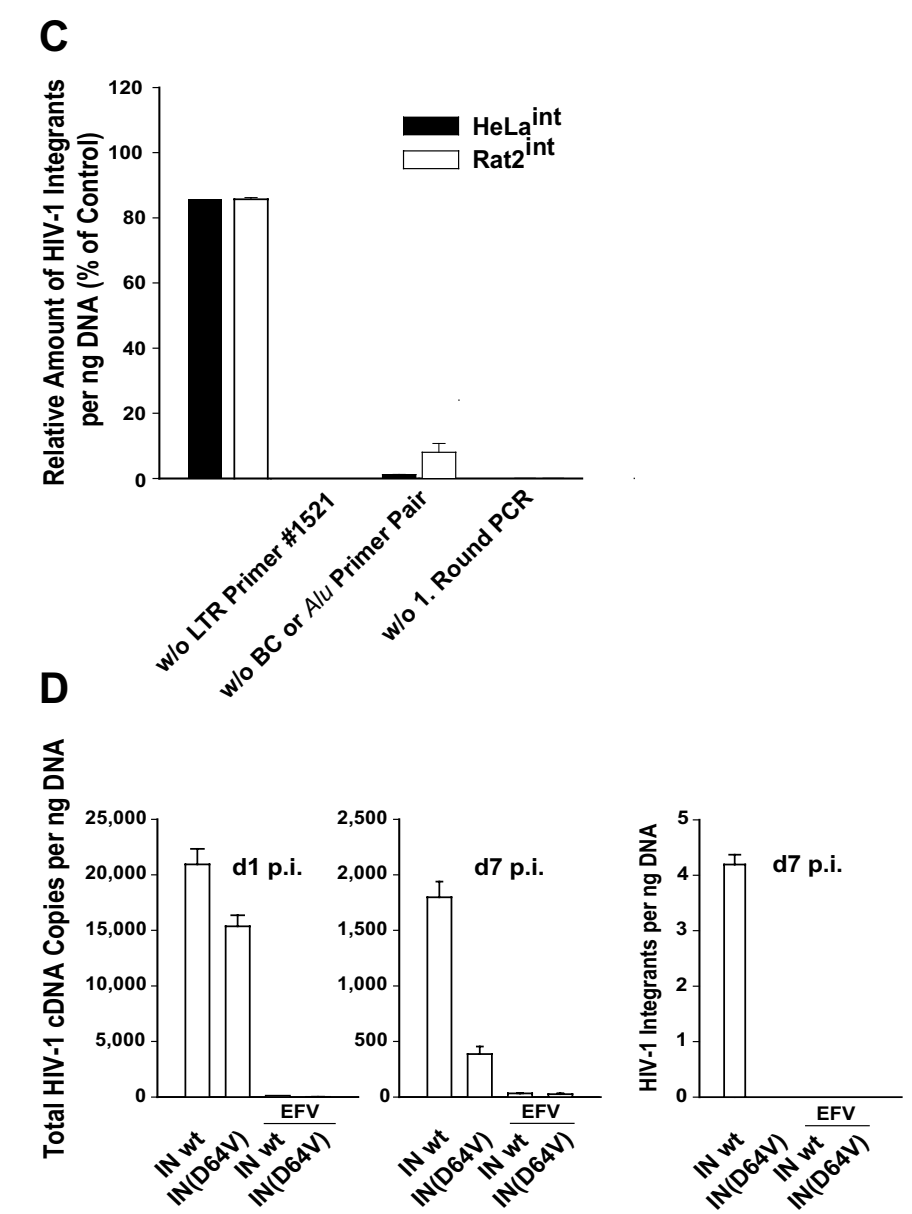

\section{Figure 4}

Establishment and validation of a real-time PCR for HIV-I integrants in rat cells. (A) Schematic of the generation of Rat2 $^{\text {int }}$ (rat) and HeLaint (human) cells, carrying HIV-I ${ }_{\text {NL4-3 }}$ E- GFP, as species-specific HIV-I integration standards. (B) PCR strategy of the nested rat integration PCR. In the first round of PCR, a segment of integrated HIV-I cDNA was amplified by one primer annealing in the HIV-I LTR (primer \#I52I) and two outward-facing primers targeting the rat ID element (primers \#I734 and \#1782). To increase specificity, LTR primer \#I52I contains a lambda-phage heel sequence at the 5'-end [30]. In a nested, second-round PCR, a lambda-specific primer (primer \#I522), a second LTR primer (primer \#I523), as well as an HIVI LTR-specific probe (probe \#I524) were employed to exclusively amplify products generated during the first-round PCR. (C) Technical validation of species-specific integration PCR on Rat2int or HeLaint [30] cells. Levels of HIV-I integrants from the complete standard PCR reaction were arbitrarily set to $100 \%$, and levels determined for several specificity controls (omission (w/o) of LTR primer \#I52I, omission (w/o) of cellular anchor primer pair (BC, \#I734 and \#I782 (rat) or Alu, \#I5I9 and \#I520 (human)), omission (w/o) of first-round PCR reaction) are given relative to that. (D) Validation of rat integration PCR. Parental Rat2 cells were infected with VSV-G pseudotyped HIV-I GFP vectors carrying either a wildtype integrase (IN wt) or catalytically inactive integrase (IN(D64V)). Where indicated, efavirenz $(5 \mu \mathrm{M})$ was added I h before infection. Cultures of infected Rat2 cells were monitored for the presence of total HIV-I cDNA on day I (left panel) or day 7 (middle panel) post infection. On day 7, cells were also analyzed for the presence of integrated HIV-I cDNA (right panel). 
Rat $2^{\text {int }}$ could be accurately determined by quantifying the absolute number of HIV-1 cDNA by real-time PCR [22], thus providing an integration standard. These values were 6.3 and 5 HIV-1 integrants per ng DNA for Rat $2^{\text {int }}$ and HeLaint, respectively.

The PCR strategy for the newly developed integrated provirus in rat cells is depicted in Fig. 4B and described in detail in the figure legend. This rat integration PCR and a human integration PCR, the latter essentially following a published protocol [30], were validated side-by-side using genomic DNA from Rat $2^{\text {int }}$ or HeLa ${ }^{\text {int }}$ cells, respectively (Fig. 4C). The numbers of HIV-1 integrants per ng DNA were set to $100 \%$. First, omission of LTR primer \#1521 from the first-round reaction resulted in a loss of the amplification signal. Second, a reaction mix without the cellular primer pair (\#1734 and \#1782 (rat); \#1519 and \#1520 (human)) yielded low signals (9.2\% for Rat $2^{\text {int }}$ and $1.3 \%$ for HeLaint), most likely due to the partial formation of single-stranded DNA from LTR-containing HIV-1 cDNA by the first-round LTR primer, as previously suggested [30]. Finally, omission of the first-round PCR reaction yielded no signal above background, indicating that second-round amplification of non-preamplified DNA is not a disturbing factor (Fig. 4C).

As an additional validation of the rat integration PCR, we quantified levels of total HIV-1 cDNA and integrated HIV1 cDNA in parental Rat 2 cells infected with either an integration-competent or an integration-defective lentiviral vector, the latter carrying the $I N(D 64 \mathrm{~V})$ catalytic core mutation [33]. On day 1 after infection, high levels of total HIV-1 cDNA, which were not detectable after efavirenz pre-treatment of cells, were amplified from Rat2 cells challenged with either lentiviral vector (Fig. 4D, left panel). In cell extracts obtained on day 7 after infection, levels of total HIV-1 cDNA had decreased to $2.8-8.6 \%$ of the levels on day 1 . Most importantly, while integrants were readily amplified by the newly developed PCR strategy at this late time point in Rat2 cells infected with the IN wt vector, provirus formation could not be detected in cells infected with the IN(D64V) vector (Fig. 4D, right panel). In summary, we have established and validated a real-time PCR for the quantitative detection of HIV-1 integrants in infected rat cells.

\section{HIV-I integrates into the genome of rat cells, infected in vitro or in vivo, as efficiently as into the genome of human cells}

To assess the kinetics of formation of different HIV-1 cDNA species and the integration frequency in infected rat cells, parental Rat2 cells and HeLa cells were simultaneously challenged with a VSV-G pseudotyped lentiviral vector. DNA extracts of cell aliquots taken from infected cultures at days 1 and 7 after infection were analyzed for
A

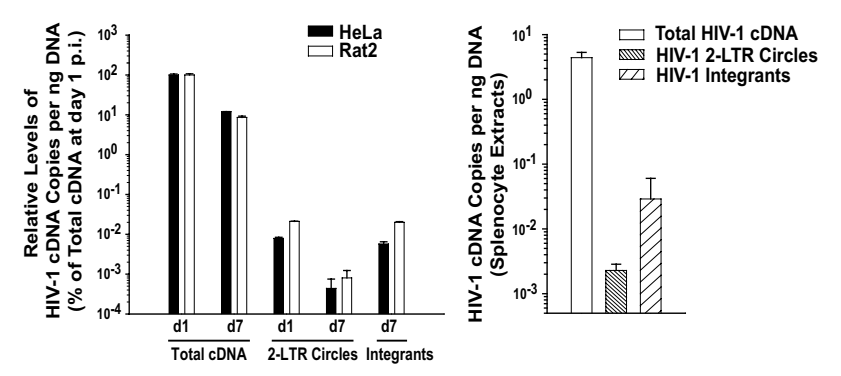

Figure 5

Integration of HIV-I into the genome occurs efficiently in infected rat cells. (A) Parental Rat2 cells and HeLa cells were exposed to VSV-G pseudotyped HIV-I GFP vectors and cultivated for 7 days. The relative levels of total HIV-I cDNA, 2-LTR circles, and integrants were quantified by specific real time PCR in extracts from cell aliquots taken at the indicated time points. All copy numbers per ng DNA are depicted relative to the levels of total HIV-I cDNA on day I after infection, levels of which were arbitrarily set to 100\%. (B) Three hCD4/hCCR5-transgenic rats and one hCCR5-single-transgenic rat were challenged intravenously

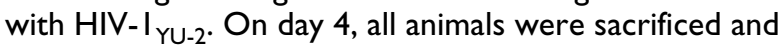
spleens removed. The levels of all three HIV-I cDNA species were quantified in splenocytes extracts relative to a rat GAPDH standard by real-time PCR. Results are presented as the arithmetic mean \pm S.E.M. of data obtained for the three double-transgenic rats.

levels of total HIV-1 cDNA and 2-LTR circles [22], as well as integrants by the assay described above (Fig. 5A). As a normalisation reference, the level of total HIV-1 cDNA obtained for each cell line at day 1 after infection was set to $100 \%$.

Notably, the relative levels of total HIV-1 cDNA and of 2LTR circles at days 1 and 7 after infection were similar in infected Rat 2 and HeLa cells. In both species, the latter episomal DNA species accounted for $\sim 0.01 \%$ (day 1 ) and $\sim 0.001 \%$ (day 7 ) of total HIV-1 cDNA. The $90 \%$ reduction likely reflects the gradual loss of episomes through cell divisions. At this late time point, the relative levels of integrants in infected Rat2 and HeLa cells were again quite similar and represented $\sim 0.02 \%$ or $\sim 0.005 \%$ of the total HIV-1 cDNA at day 1 , respectively. Together, the relative abundance of these three HIV-1 cDNA species was remarkably similar in these infected cultures of adherent cells of rat and human origin. Unfortunately, reliable detection of HIV-1 integrants in cultured primary T-cells was precluded by a virus stock production-related contamination with proviral plasmid DNA that was partially resistant to DNAse treatment (data not shown). 
In a recent infection study in hCD4/hCCR5-transgenic rats, we observed that this plasmid contamination of virus stocks is apparently lost or degraded in vivo, allowing the exclusive detection of HIV-1 cDNAs synthesized de novo in splenocyte extracts [22]. Consequently, we challenged three hCD4/hCCR5-transgenic rats and one hCCR5-single-transgenic control rat intravenously with HIV-1 $1_{\mathrm{YU}-2}$. Four days after infection, animals were sacrificed, and the spleens, which harbor high levels of CD4 T-lymphocytes, were removed. Levels of total HIV-1 cDNA in splenocyte extracts from infected hCD4/hCCR5-transgenic rats ranged from 3.2 to 5.3 copies per ng DNA (Fig. 5B). As important controls of specificity, neither HIV-1 cDNA nor HIV-1 integrants could be amplified from extracts of the hCCR5-transgenic animal challenged with the identical virus inoculum (data not shown). Furthermore, no HIV-1 integrants could be amplified from splenocyte DNA derived from efavirenz-treated, infected hCD4/hCCR5transgenic rats ([22] and data not shown). Collectively, these results demonstrate that the signals obtained from samples derived from double-transgenic rats indeed represent de novo-synthesized HIV-1 cDNA. Here, integrants were detected at a frequency of $0.03 \pm 0.02$ copies per ng DNA, representing $0.65 \%$ of the total HIV-1 cDNA at this time point after infection. Relative levels of 2-LTR circles were clearly less abundant $(0.0023 \pm 0.0006$ copies per ng of DNA), representing $0.05 \%$ of the total HIV-1 cDNA.

Thus, HIV-1 integrants can be quantitatively detected in splenocyte extracts from hCD4/hCCR5-transgenic rats following in vivo challenge, and the relative representation of the three HIV-1 cDNA species analyzed mirrors the results obtained for in vitro infection studies in cell lines from both species (Fig. 5A). This suggests that the integration frequency into the genome of rat T-lymphocytes is not impaired.

\section{Single-cell analysis reveals that early HIV-I gene expression is diminished in infected primary rat T-cells}

Subsequently, we sought to compare levels of early HIV gene expression in primary T-cells on a single cell level. Activated T-cell cultures from hCD4/hCCR5-transgenic rats and human donors were infected with single-round HIV-1 $1_{\text {NL4-3 }}$ E- GFP viruses pseudotyped with YU-2 Env and analyzed for the expression of the GFP reporter, at the nef locus, by flow cytometry.

The percentages of GFP-expressing T-cells 3 days after infection were comparable and efavirenz-sensitive in both species (Fig. 6A (gate R2)), and only donor-specific variations were noted (Fig. 6B). Most remarkably, however, the intensity of GFP expression, reflected by the mean fluorescence intensity (MFI) of individual infected cells analyzed, drastically differed: infected human T-cells displayed a rather distinct population of GFP high- expressing cells (Fig. 6A (upper horizontal panel); quantification in Fig. 6C), whereas T-cells from hCD4/hCCR5transgenic rats exhibited only rather low levels of expression of the early gene product (Fig. 6A, middle horizontal panel; Fig. 6C). On average, this difference in gene expression was 5- to 8-fold, irrespective of the viral entry route $\left(\mathrm{HIV}-1_{\mathrm{YU}-2}\right.$ Env, HIV-1 $1_{\mathrm{JR}-\mathrm{FL}}$ Env, VSV-G) (Fig. 6A,C; Fig. 7A). Interestingly, this species-dependent gap was even more pronounced for an HIV-2 $2_{\text {ROD-A }} \mathrm{E}^{-}$GFP reporter virus, which showed a 21-fold difference (Fig. 7B). Remarkably, primary T-cells from native BALB/c mice were largely refractory to infection by VSV-G pseudotyped HIV- $1_{\mathrm{NL} 4-3} \mathrm{E}^{-}$ GFP (Fig. 6A, lower horizontal panel, and 6B), and virtually no GFP-positive cells could be detected despite efficient virion entry (data not shown), consistent with previous reports $[5,14]$.

We next asked whether this striking difference in gene expression levels between primary human and rat T-cells could be due to species-specific differences in the kinetics of HIV-1 gene expression. Monitoring GFP expression over the course of 11 days (Fig. 7B), rat T-cells infected with the replication-deficient HIV-1 reporter virus did not reveal significant alterations in their levels of early gene expression. GFP expression levels in human reference cultures peaked at days 6-8 after infection and subsequently decreased, most likely due to gene silencing or loss of infected cells from the culture. Thus, a mere delay in viral gene expression in infected rat T-cells seems unlikely.

Furthermore, this phenotype turned out to be largely species-specific: the defect in early HIV-1 gene expression was seen most drastically in infected T-cell lines from rats, with a factor of difference ranging from 6- to 100-fold (Fig. 7C), and also in adherent cell lines, albeit less pronounced (4- to 10 -fold factor of difference, Fig. 7D). Interestingly, primary macrophages were an exception, revealing comparable levels of early HIV-1 gene expression in both species after infection with the VSV-G pseudotyped HIV-1 $1_{\mathrm{NL} 4-3} \mathrm{E}-\mathrm{GFP}$ reporter virus (Fig. $7 \mathrm{E} ; \mathrm{p}=0.2$; n.s.).

Collectively, these flow cytometric data at single cell level demonstrate a major post-integrational limitation in viral gene expression in most rat-derived cells, which may be a key reason for the failure of primary T-cells from hCD4/ hCCR5-transgenic rats to support HIV-1 replication.

\section{Transient expression of human Cyclin $\mathrm{TI}$ in rat T-cells boosts early HIV gene expression}

On a molecular level, the inability of mouse Cyclin T1 to support the Tat-mediated enhancement of HIV transcription has been mapped to the $\mathrm{C} 261 \mathrm{Y}$ variation in the mouse protein [34] (parts of the amino acid sequence are shown in Fig. 8A). Intriguingly, rat Cyclin T1 (genebank: 

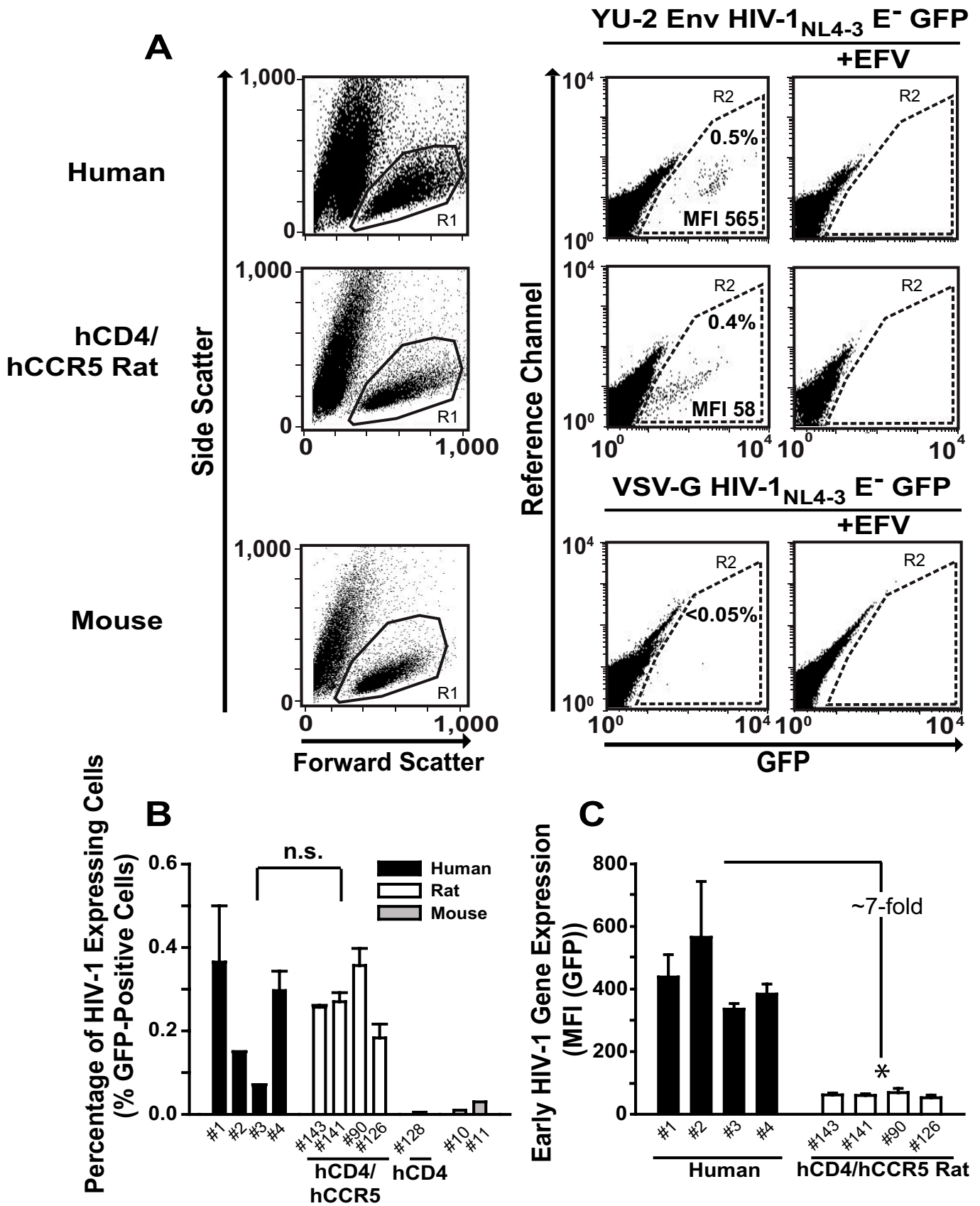

Figure 6

Activated primary rat T-cells exhibit a profound block to HIV-I replication at the level of early HIV-I gene expression. (A) Representative FACS dot plots of T-cells from a human donor, a hCD4/hCCR5-transgenic rat, and a BALB/c mouse infected with the indicated HIV-I GFP reporter viruses (50 ng P24 CA per 2-3 × $10^{6}$ cells) and analyzed for GFP expression on day 6 after infection. Viable cells were identified by gating on the live lymphocyte population (gate RI) in the FSC/SSC plot (left vertical panels). Gate R2 defines the GFP-positive subpopulation of gate RI. Shown are results obtained from cells infected in the absence (middle vertical panels) and presence of efavirenz (EFV) (right vertical panels). (B) Percentage of GFP-positive cells obtained for T-cell cultures from four human donors, four hCD4/hCCR5-transgenic rats, and two BALB/ $c$ mice which had been infected as described in $A(P=0.77$; n.s.) (C) MFI(GFP) of infected human and rat T-cell cultures shown in $B(p=0.02 ; *=$ significant $)$. 


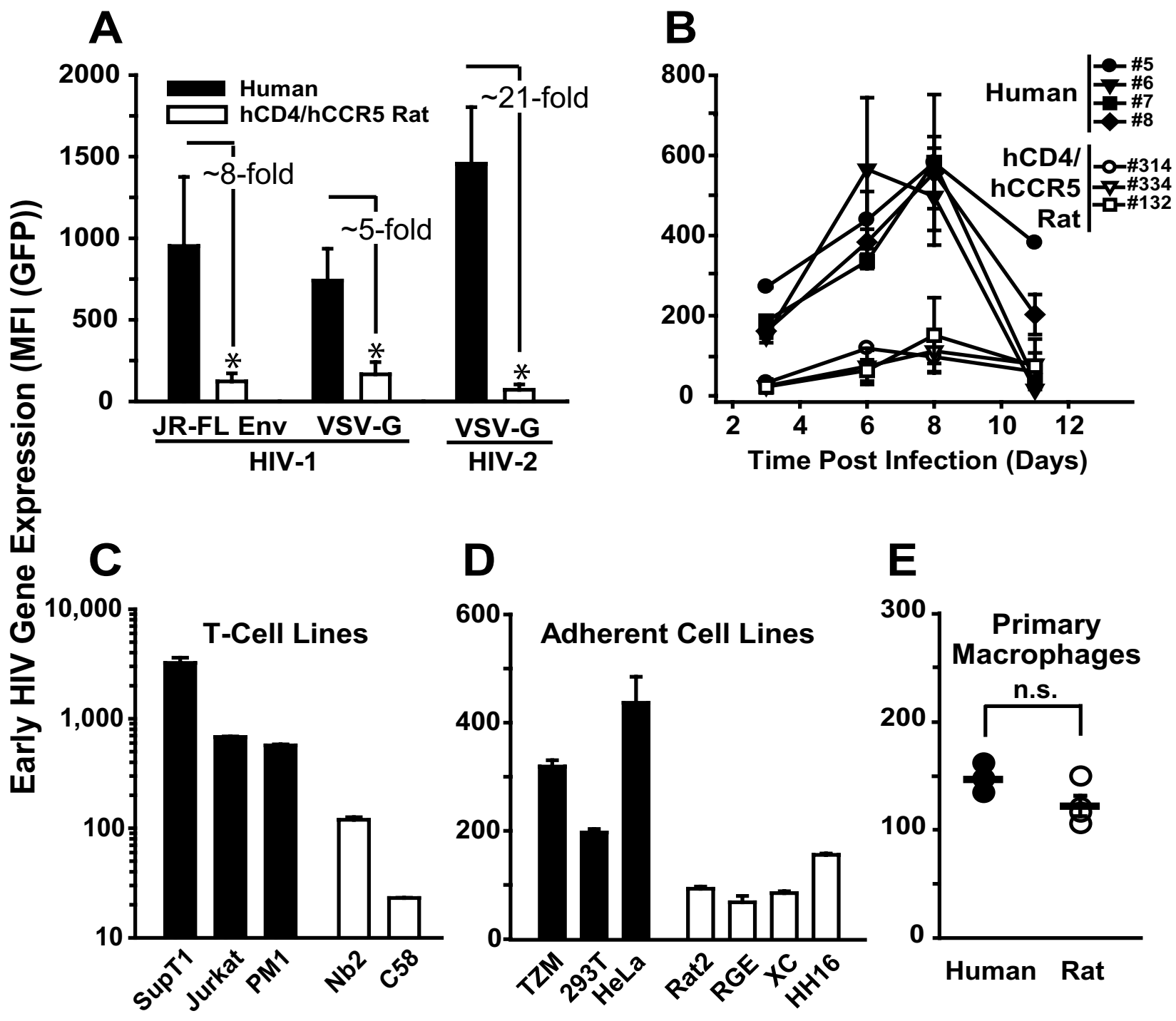

Figure 7

Early HIV-I gene expression is also diminished in infected rat cell lines, but not in infected primary rat macrophages. (A) T-cell cultures were challenged with HIV-I ${ }_{N L 4-3} E-G F P$ pseudotyped with either JR-FL Env $(n=2)$ or VSV-G (human $(n=12)$; rat $(n=24)$ ), or challenged with VSV-G pseudotyped HIV-2 ROD-A E- GFP (human $(n=7)$; rat $(n=12)$ ) and analyzed for GFP expression at day 3 after infection as described in Fig. 6. Results represent the arithmetic mean \pm S.E.M. of the indicated number of independent T-cell cultures $(\mathrm{P}=0.009 ; *=$ significant). (B) Kinetics of GFP expression in primary T-cell cultures from human donors or hCD4/hCCR5-transgenic rats infected with single-round YU-2 Env pseudotyped HIV- NL4-3 $\mathrm{E}^{-}$ GFP. The percentage of GFP-positive cells was quantified every 2-3 days by flow cytometry. Results are the arithmetic mean \pm S.D. from individual T-cell cultures. (C) Human T-cell lines SupTI, Jurkat, or PM-I, and rat T-cell lines Nb2 or C58, as well as (D) human adherent cell lines TZM, 293T, or HeLa, and rat adherent cell lines Rat2, RGE, XC, or HHI6, and (E) primary macrophages from both species (human $(n=3)$; rat $(n=4)$ ) were exposed to VSV-G pseudotyped HIV-I ${ }_{N L 4-3} E_{-}$GFP at a low MOI to achieve single cell infections. The MFI of GFP expression was determined on day 3 after infection $(p=0.2 ; n . s$.). Results shown in (C-D) represent the arithmetic mean \pm S.D. of triplicates. Circles in (E) indicate the arithmetic mean of triplicates from one experiment and the horizontal bar shows the arithmetic mean \pm S.E.M. of all donors/animals analyzed. 
A
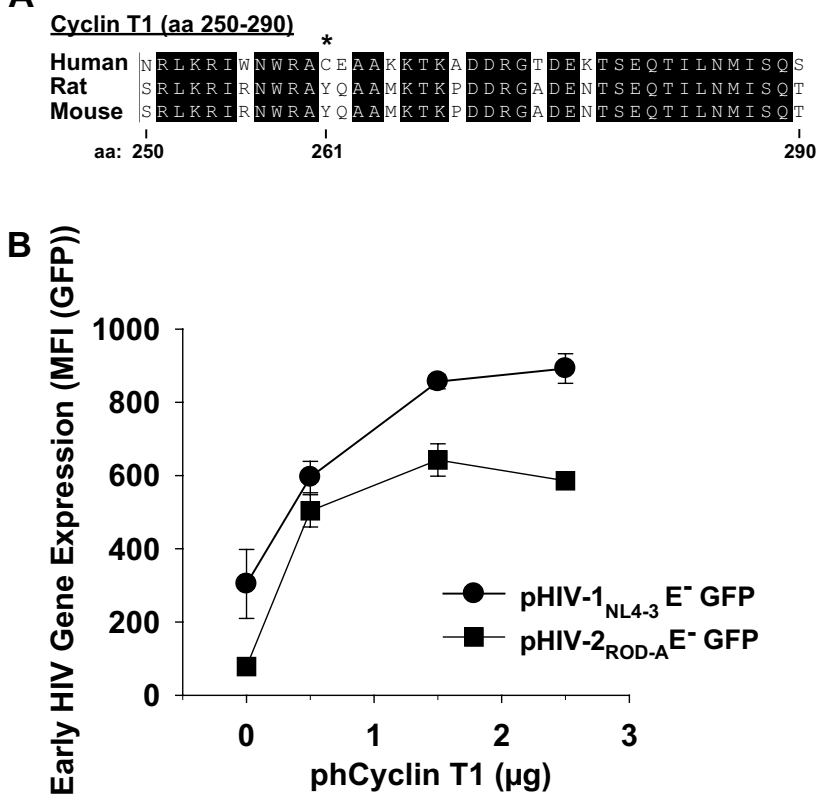

Figure 8

Transient expression of human Cyclin $\mathrm{TI}$ in primary rat T-cells boosts early HIV gene expression. (A) Sequence alignment of amino acids 250-290 of human, rat and mouse Cyclin TI. * depicts the critical amino acid position 26I. (B) Proviral PHIV-I NL4-3 $_{\text {GFP or PHIV-2 }}$ ROD-A GFP constructs were co-transfected with increasing amounts of an expression vector encoding for either human Cyclin TI (phCyclin TI) or no transgene (pcDNA3.I), and cells were analyzed for GFP expression $20 \mathrm{~h}$ later by flow cytometry.

Ccnt1_predicted XM_235633) shares around 96\% sequence homology with the mouse orthologue, including the critical C261Y variation ([4]; Fig. 8A).

To rapidly assess whether expression of human Cyclin T1 can affect HIV gene expression in primary rat T-cells we performed transient co-transfection studies employing a recently developed species-adapted non-viral gene delivery method based on the nucleofection technology [35]. Proviral pHIV-1 $1_{\text {NL4-3 }}$ GFP or pHIV-2 ${ }_{\text {ROD-A }}$ GFP constructs were co-transfected with increasing amounts of an expression vector encoding for either human Cyclin T1 or no transgene, and cells were analyzed for GFP expression 20 $\mathrm{h}$ later by flow cytometry. Remarkably, expression of human Cyclin T1 enhanced early HIV gene expression in a concentration-dependent and saturable manner in these primary rodent T-cells (Fig. 8B). As a control of specificity, human Cyclin T1 expression did not affect reporter gene expression from a CMV immediate early promoter-driven construct, pEGFP-N1, in nucleofected rat T-cells (data not shown). Moreover, co-transfection of phCyclin T1 and these proviral constructs into primary T-cells from human donors did not significantly alter levels of HIV gene expression (data not shown), indicating that physiological levels of Cyclin T1 are not limiting in these cells.

Collectively, these transient ex vivo studies suggest an underlying transcriptional defect linked to the non-functional rat orthologue and demonstrate a beneficial effect of Cyclin T1 of human origin on HIV gene expression in primary rat T-cells.

\section{Discussion}

An in-depth assessment of the individual steps in the viral replication cycle in primary target cells is critical for generating a highly HIV-1-permissive immunocompetent rodent model for HIV-1 infection. Here we used quantitative assays to probe consecutive steps in the early phase of HIV-1 infection. We found that virion fusion, reverse transcription, nuclear import, and HIV-1 integration into the host genome occur with similar efficiencies in primary $\mathrm{T}$ cells from hCD4/hCCR5-transgenic rats and humans. However, one step downstream in the replication cycle, we find viral gene expression to be greatly diminished in infected T-cells from rats, sixfold for HIV- $1_{\text {NL4-3 }}$ and 20fold for HIV-2 $2_{\text {ROD-A }}$ reporter viruses, relative to human references, identifying the next relevant replication barrier to be tackled in this species. Furthermore, we show a beneficial effect of Cyclin T1 of human origin on HIV gene expression in primary rat T-cells, providing a strong rationale for the generation of a novel human Cyclin T1transgenic rat line.

We began our examination with the entry of the virus into the cell. Expression of hCD4 and a major human chemokine coreceptor is required for entry into cells of nonhuman origin, but the efficiency of virus entry into rodent cell lines expressing high levels of the HIV-1 receptor/ coreceptor complex was thought to be very low $(0.25-$ $17 \%$ of human cells) [9]. To directly compare the efficiencies of R5 HIV-1 entry in T-cells from hCD4/hCCR5-transgenic rats and human reference cultures, we employed a sensitive and specific virion-fusion assay [22,24,25]. The HIV-1 receptor/coreceptor complex at the expressed surface levels is fully functional in rats, implying correct posttranslational modifications, receptor trafficking, and cellsurface topology of both receptor components. Moreover, our results provide the first quantitative demonstration of the success of entry receptor transgenesis towards the development of an HIV-1-permissive rodent model.

Next we assessed the efficiency and kinetics of HIV-1 cDNA synthesis, nuclear import of the preintegration complex (2-LTR circle formation), and provirus integration by real-time PCR. Our post-entry analyses in primary T-cells and a fibroblast cell line from rats suggest an efficient progression of the viral replication cycle from reverse 
transcription over nuclear import to integration. For primary T-cells, technical limitations did not allow us to conduct a direct rat-human species comparison for HIV cDNA synthesis. However, comparable levels of HIV entry and 2LTR circle formation, representing the preceding and subsequent step in the replication cycle, strongly suggest that reverse transcription occurs efficiently in primary rat $\mathrm{T}$ cells, although subtle quantitative differences cannot be excluded.

These observations argue that rat-derived cells are intrinsically more permissive for these early post-entry steps in HIV-1 infection than cells from other small animals, although this difference is not understood at a molecular level. In this context, two other studies found that defects in reverse transcription and/or nuclear import in infected mouse T-cells severely impede viral gene expression and appear to be recessive in nature $[5,14]$. Furthermore, aberrant intracytoplasmic trafficking of the reverse transcription complex in rabbit SIRC cells may be an underlying reason for a reduced HIV-1 cDNA synthesis in this rodentlike species [13].

Contrasting the intact HIV-1 entry and early post-entry steps, we identified a limitation at the level of early HIV-1 gene expression in primary T-cells from double-transgenic rats that was independent of the viral entry route and that was apparent in all T-cell lines and adherent cell lines analyzed. We used flow cytometry to quantify early HIV-1 gene expression through the MFI of GFP as a surrogate for Nef. This approach allowed a resolution at a single-cell level in infected cultures rather than bulk analyses using luciferase or chloramphenicol-acetyl-transferase reporter systems applied in earlier studies $[4,9,11,36]$. Our experimental strategy was particularly useful for the cross-species comparison since the analysis of gene expression is much less affected by differences in the efficiency of preceding steps in the replication cycle. Specifically, earlier studies assessed HIV-1 gene expression in rodent cell lines after infection with VSV-G HIV-1 luciferase reporter viruses $[4,7,9]$, based on the assumption that the efficiency of VSV-G-mediated entry is comparable across species. However, in quantitative virion-fusion assays, we found generally greater VSV-G susceptibility in rat cells than human references, ranging from 3- to 10-fold for an identical inoculum in adherent cell lines (Rat2 versus HeLa), as well as in primary T-cells and macrophages (data not shown). This previously unrecognized difference may have led to an overestimation of the capacity of Rat 2 cells to support HIV-1 gene expression $[4,7,9]$. Moreover, alternative transcriptional assays based on the transient transfection of LTR reporter and Tat expression constructs rely on a normalisation of transfection efficiency that involves a third, typically CMV immediate early promoter-driven reporter, for which species- and cell type-specific differences in the activity may be an additional confounding problem.

We reasoned that an impaired activity of the Tat-dependent HIV-1 LTR transactivation [16,17] may underlie the inefficient early gene expression for HIV-1 $1_{\mathrm{NL} 4-3}$ and HIV$2_{\text {ROD-A }}$ reporter viruses in primary rat T-cells. In mice, the inability of Cyclin T1 to support the efficient interaction with the TAR element when bound to Tat was functionally mapped to one essential amino acid (C261Y) $[18,34,37,38]$, and intriguingly, rat Cyclin $\mathrm{T} 1$ and the mouse orthologue both have a tyrosine at this position [4]. Here, using recently developed technology [35], we could demonstrate a marked enhancement of HIV gene expression in primary rat T-cells following transient expression of human Cyclin T1. This suggests that the impaired HIV gene expression, at least in part, is due to a transcriptional defect linked to a non-functional rat Cyclin T1. Furthermore, these ex vivo studies provide a sound rationale for the generation of human Cyclin T1-transgenic rats as an additional genetic modification of the hCD4/hCCR5-transgenic rat model of HIV infection.

In addition, and despite the fact that the frequency of HIV1 integration into the rat genome appeared to be normal, an underlying defect in the HIV-1 integration site selection must be considered. The efficiency of viral transcription is governed by characteristics of the chromatin environment at the integration site [39]. Whereas HIV-1 preferentially integrates within active transcription units [40], MLV favours integration at transcription start regions $[41,42]$. The dependence of this process on host factors, such as lense epithelium-derived growth factor (LEDGF/ p75), that is required for HIV-1, but not for MLV integration $[43,44]$, makes this a candidate step for species-specific disturbances of integration site selection.

As an interesting observation, infected macrophages pose an exception to the otherwise species-specific impairment at the level of early HIV-1 gene expression in the rathuman species comparison. This is particularly noteworthy since macrophages from hCD4/hCCR5-transgenic rats are the only rodent cells known to support a productive and spreading HIV-1 infection, albeit at lower levels than in human monocyte-derived macrophages [4,11]. Providing an intriguing explanation, HIV-1, in part, exploits a distinct set of nuclear transcription factors and alternative mechanisms of transcriptional regulation in macrophages than in other cell types, including T-cells (reviewed by [45-47]). From the perspective of viral evolution, it is remarkable that macrophages are the only primary cell type that is permissive for all lentiviruses in their respective host [48]. Their marked phenotypic difference in the relative ability to support early gene expression of HIV$1_{\text {NL4-3 }}$ and HIV-2 $2_{\text {ROD-A }}$ reporter viruses compared to T-cells 
may reflect their higher dependence on specific transcription factors, including NF-kB and NFAT-1.

Pursuing a conceptually different approach to the generation of an HIV small animal model, several HIV xenotransplant models have been developed by introducing human hematopoietic cells or foetal tissues into immunodeficient strains of mice. Such animals support local HIV replication in grafts or, following recent advancements, also systemic HIV replication with high level viremia (reviewed by [49]). Unfortunately, adaptive immune responses in such "humanized" mice were reported to be low or absent, and these technically challenging models are not amenable to predictive highthroughput screenings of drug candidates.

\section{Conclusion}

Collectively, the efficiency of all early steps of the HIV-1 replication cycle in CD4 T-cells from hCD4/hCCR5-transgenic rats, in clear contrast to mice, up to and including provirus formation is high. These results are encouraging for the block-by-block development of a fully permissive rat model of HIV-1 disease. From a different perspective, these results provide an important validation of these HIV-susceptible small animals by underscoring the predictive value of hCD4/hCCR5-transgenic rats as a model for the evaluation of antiviral compounds targeting early events of HIV-1 replication [22]. Furthermore, the demonstration of a marked quantitative limitation at the level of viral gene expression in rat CD4 T-cells and, importantly, the beneficial effect of human Cyclin T1 in these primary cells, provide the basis for the design of strategies to overcome it.

\section{Methods \\ Animals}

Generation and initial characterization of hCD4/hCCR5transgenic rats on an outbred Sprague-Dawley background have been reported [11]. Female BALB/c mice were obtained from Charles River Laboratories (Sulzfeld, Germany). Animals were housed in the central animal facility of the University of Heidelberg. Animal experiments were conducted according to the German animal welfare act and with authorization of the Regierungspräsidium Karlsruhe (35-9185.81/G-100/02 and 34395) and supervised by animal welfare officers of the University of Heidelberg.

\section{Cells}

Cultures of primary T-cells and macrophages from randomly selected human donors and transgenic rats and $\mathrm{BALB} / \mathrm{c}$ mice were generated, activated, and cultivated as reported $[11,22,35,50]$. Rat cell lines Rat2 (rat fibroblastlike cell line [ATCC CRL-1764]), RGE (rat glomerular endothelial cell line [DSMZ ACC 262]), XC (rat sarcoma cell line [DSMZ ACC 118]), HH16.cl.4 (rat mammary tumor cell line [DSMZ ACC 358]), C58 (rat T-cell lymphoma [ATCC TIB-236]), and Nb2 (rat T-cell lymphoma) [11] were cultivated as recommended by the original sources. Human cell lines SupT1, Jurkat, HeLa, PM-1, TZM-bl and 293T were cultivated as reported $[4,50]$.

\section{Virus stocks}

Generation of replication-competent HIV-1 $1_{\mathrm{YU}-2}$ and HIV$1_{\mathrm{R} 7 / 3} \mathrm{YU}-2$ Env GFP stocks has been reported [11]. HIV$1_{\mathrm{YU}-2}$ virions carrying $\beta$-lactamase-Vpr chimeric fusion proteins (BlaM-Vpr) were produced by triple-transfection of 293T cells as described [24] with pYU-2 proviral DNA $(60 \mu \mathrm{g}), \mathrm{pBlaM}-\mathrm{Vpr}(20 \mu \mathrm{g})$, and pAdVantage $(8 \mu \mathrm{g})$ vectors (Promega, Madison, WI) per $15-\mathrm{cm}^{2}$ dish by calcium phosphate DNA precipitation. The molecular clone pNL4-3 E- GFP, carrying an egfp gene within the nef locus driven by the 5'- LTR, was a kind gift of Dr. Nathaniel Landau (New York University, New York, NY) [51] via the NIH AIDS Research and Reference Reagent Program. Pseudotyping with VSV-G, JR-FL Env and YU-2 Env was performed as reported [4]. All HIV-1 stocks were characterized for p24 CA concentration by antigen enzymelinked immunosorbent assay and/or for infectious titer on TZM-bl cells [50]. The molecular clone pHIV-2 $2_{\text {ROD-A }}$ was a gift from Dr. Matthias Dittmar (Department of Virology, University of Heidelberg, Germany) [52]. Lentiviral vectors were generated by triple-transfection of 293T with $\mathrm{p} \Delta$ R8.91, pHR.GFP [53] and pVSV-G by calcium phosphate DNA precipitation and were DNAse-treated (Turbo DNAse, Ambion, Dresden, Germany) for $1 \mathrm{~h}$ at $37^{\circ} \mathrm{C}(1$ unit DNAse $/ 10 \mu \mathrm{l}$ of concentrated virus stock). MoMLVGFP was constructed by introducing the egfp gene driven from an internal ribosomal entry site (IRES) into the untranslated region between the env gene and the 3'-LTR of MoMLV at unique NotI/MluI sites. Titers and replication kinetics of MoMLV-GFP and MoMLV wildtype were similar, and GFP expression of the recombinant was stable over several passages on mouse fibroblasts (data not shown).

\section{HIV-I virion-fusion assay}

The HIV-1 virion-fusion assay based on flow cytometry was conducted essentially as described [22,24,25]. Briefly, primary T-cells were pretreated with the indicated concentrations of enfuvirtide (Roche, Indianapolis, IN), TAK779, AMD3100 (kind gifts from José Esté) or anti-hCCR5 mAb 2D7 (BD Pharmingen, San Diego, CA) for 15-30 min when indicated. Subsequently, cells were challenged with HIV-1 $1_{\mathrm{YU}-2}$ BlaM-Vpr virions (50 ng p24 CA per $2 \times$ $10^{6} \mathrm{~T}$-cells) for 3-4 h, washed, and then loaded with CCF2/AM dye overnight. Fusion was monitored with a three-laser BD FACSAria Cell Sorting System (Becton Dickinson, San Jose, CA). 


\section{Quantification of HIV-I 2-LTR circles and total HIV-I cDNA}

The relative amounts of 2-LTR circles and/or total HIV-1 cDNA in extracts from ex vivo-infected T-cell cultures or in vivo-infected splenocytes were determined by real-time PCR with the ABI 7500 sequence detection system (Applied Biosystems, Foster City, CA) essentially as described [22]. Results for HIV-1 cDNA species were normalized to the amount of cellular DNA, which was quantified in a parallel amplification of rat GAPDH gene DNA or human RNaseP gene DNA (Applied Biosystems). Genomic standards were derived from dilutions of genomic DNA extracted from uninfected primary rat or human T-cell cultures and uninfected Rat 2 or HeLa cells. The lowest limit of detection was 0.001 2-LTR circle copies per ng DNA and 0.02 total HIV-1 cDNA copies per ng DNA. All samples were run in duplicate or triplicate. Data analysis was performed using the 7500 System Software (Applied Biosystems).

\section{Quantification of integrated HIV-I DNA}

The procedure used to establish the quantitative nested PCR strategy for HIV-1 integrants in the rat genome and the generation of cell lines that served as integration standards, Rat $2^{\text {int }}$ and HeLaint, is described in the Results section and in Fig. 4. Briefly, in a first PCR reaction, HIV1 integrants were amplified by one primer annealing to the LTR (primer \#1521 [30]), which contains a lambdaphage heel sequence at the 5 ' end, and by two outwardfacing primers that target the highly redundant identifier (ID) consensus sequence within the rat BC1 RNA gene (primers \#1734, 5'-GGTAACTGGCACACACAACC-3' and \#1782, 5'-CTGAGCTAAATCCCCAACCC-3'). The conditions for the first PCR were (a) $3 \mathrm{~min}$ at $94^{\circ} \mathrm{C}$, (b) 12 cycles of $30 \mathrm{sec}$ at $94^{\circ} \mathrm{C}, 30 \mathrm{sec}$ at $57^{\circ} \mathrm{C}, 4 \mathrm{~min}$ at $72^{\circ} \mathrm{C}$, and (c) $10 \mathrm{~min}$ at $72^{\circ} \mathrm{C}$. The second PCR amplified the first-round amplicon with a lambda-specific primer (primer \#1522 [30]) and an LTR primer (\#1523, 5'TGACTAAAAGGGTCTGAGGGATCT-3') and an LTR-specific probe (probe \#1524, 5'-(FAM)-TTACCAGAGTCACACAACAGACGGGCA-(rhodamine (TAMRA)-3'). The second-round cycling conditions were identical to those used to determine the total amounts of HIV-1 cDNA and 2-LTR circles [22]. For the PCR to detect HIV-1 integrants in human cells, the conditions and reagents were identical, except that a primer pair targeting the Alu elements served as cellular anchor primers (forward primer \#1719 [30] and reverse primer \#1720 [54]). For each integration PCR, a control reaction in which the cellular primer pair was omitted was run in parallel. This value was routinely subtracted from the total signal. For standard curves, dilutions of genomic DNA from Rat 2 int and HeLa $^{\text {int }}$ covering 3.9 logs were used. The lowest detection standard of the PCR was 0.07 and $0.05 \mathrm{HIV}-1$ integrants per ng DNA, for integrated provirus in rat and human genomic DNA, respectively.

\section{In vivo-infections in transgenic rats}

Three hCD4/hCCR5-transgenic rats (age: 11 weeks; weights: 196-222 g) were anesthetized and challenged by tail vein injection via a plastic catheter with $\mathrm{HIV}-1_{\mathrm{YU}-2}$ (corresponding to $3000 \mathrm{ng}$ p24 CA per rat), essentially as described $[11,22]$. One hCD4-single-transgenic rat, inoculated with the identical virus dose, served as negative control. On day 4 post-challenge, all animals were sacrificed with $\mathrm{CO}_{2}$ and bilateral thoracotomy, and spleens were removed. Total DNA was prepared from single-cell suspensions of splenocytes with DNeasy tissue kits (Qiagen, Hilden, Germany) and analyzed by real-time PCR.

\section{HIV-I single-round infections}

Activated primary T-cells and T-cell lines $\left(3 \times 10^{6}\right)$, adherent cell lines $\left(0.8-1 \times 10^{5}\right)$, or primary macrophages $(\sim 2$ $\times 10^{5}$ cells) from rats and humans were pretreated with efavirenz (10 $\mu \mathrm{M}, 1 \mathrm{~h}$, Bristol-Myers Squibb, Uxbridge, UK) where indicated and subsequently challenged with single-round HIV- $1_{\mathrm{NL} 4-3} \mathrm{E}^{-} \mathrm{GFP}$ reporter viruses pseudotyped with the indicated Envs (corresponding to 50-200 ng HIV-1 p24 CA). On day 3 after infection, the percentage of GFP-positive cells and the GFP mean fluorescence intensity (MFI(GFP)) were determined on a FACSCalibur using BD CellQuest Pro 4.0.2 Software (BD Pharmingen).

\section{Nucleofection of primary rat $T$ cells}

Activated primary rat T cells were transfected by nucleofection as described [35]. For the analysis of the effect of transiently expressed human Cyclin T1, the expression vector phCyclin T1 [15] was utilized. Flow cytometric analysis of viable, GFP-positive cells was performed 20 hours post nucleofection as reported.

\section{Competing interests}

The author(s) declare that they have no competing interests.

\section{Authors' contributions}

CG, NM, HGK, WCG, and OTK designed the study. CG conducted the majority of the experiments. NM performed provirus/CyclinT1 cotransfection studies in primary T-cells. IA generated virus stocks and primary cell cultures and performed and analyzed infection experiments. VH cloned the MoMLV-GFP construct and characterized the recombinant virus. HMT conducted and analyzed the mouse T-cell infection experiment. HGK assisted CG and OTK with data interpretation. CG and OTK wrote the paper. All authors approved the final manuscript. 


\section{Acknowledgements}

We are grateful to Drs. Matthias Dittmar, José Esté, Martin Hartmann, Nathaniel Landau, and Didier Trono for the gift of reagents. We thank Mrs. Julia Lenz and Dr. Blanche Schwappach for TBD FACSAria analysis and Drs. Andreas Jekle and Marielle Cavrois for initial virion-fusion assays. We thank Drs. Valerie Bosch, Oliver Fackler, and Mrs. Silvia Geuenich and HannaMari Tervo for comments on the manuscript. We thank Mr. Reinhold Schmitt and Silvio Krasemann for animal handling. We are grateful to Mr. Gary Howard for editorial assistance.

This work was supported by the Deutsche Forschungsgemeinschaft (grant $\mathrm{Ke} 742 / 2$ ) and the European TRloH consortium (EU project LSGH-2003503480) to O.T.K., and from NIH grant ROI-MH64396 to W.C.G. and subcontract R005I-B from the J. David Gladstone Institutes to O.T.K. N.M. is indebted to the Landesstiftung Baden-Württemberg for financial support.

\section{References}

I. Kinter A, Arthos J, Cicala C, Fauci AS: Chemokines, cytokines and HIV: a complex network of interactions that influence HIV pathogenesis. Immunol Rev 2000, 177:88-98.

2. Berger EA: HIV entry and tropism: the chemokine receptor connection. Aids 1997, I I(Suppl A):S3-16.

3. Berger EA, Murphy PM, Farber JM: Chemokine receptors as HIVI coreceptors: roles in viral entry, tropism, and disease. Annu Rev Immunol 1999, I 7:657-700.

4. Keppler OT, Yonemoto W, Welte FJ, Patton KS, lacovides D, Atchison RE, Ngo T, Hirschberg DL, Speck RF, Goldsmith MA: Susceptibility of rat-derived cells to replication by human immunodeficiency virus type I. J Virol 200I, 75:8063-8073.

5. Baumann JG, Unutmaz D, Miller MD, Breun SK, Grill SM, Mirro J, Littman DR, Rein A, KewalRamani VN: Murine T cells potently restrict human immunodeficiency virus infection. J Virol 2004, 78: I2537- 12547

6. Feng Y, Broder CC, Kennedy PE, Berger EA: HIV-I entry cofactor: functional cDNA cloning of a seven-transmembrane, $G$ protein-coupled receptor. Science 1996, 272:872-877.

7. Mariani R, Rutter G, Harris ME, Hope TJ, Krausslich HG, Landau NR: A block to human immunodeficiency virus type I assembly in murine cells. J Virol 2000, 74:3859-3870.

8. Speck RF, Penn ML, Wimmer J, Esser U, Hague BF, Kindt T], Atchison RE, Goldsmith MA: Rabbit cells expressing human CD4 and human CCR5 are highly permissive for human immunodeficiency virus type I infection. J Virol 1998, 72:5728-5734.

9. Bieniasz PD, Cullen BR: Multiple blocks to human immunodeficiency virus type I replication in rodent cells. J Virol 2000, 74:9868-9877.

10. Browning J, Horner JW, Pettoello-Mantovani M, Raker C, Yurasov S, DePinho RA, Goldstein H: Mice transgenic for human CD4 and CCR5 are susceptible to HIV infection. Proc Natl Acad Sci USA 1997, 94: |4637-|464|.

11. Keppler OT, Welte FJ, Ngo TA, Chin PS, Patton KS, Tsou CL, Abbey NW, Sharkey ME, Grant RM, You Y, Scarborough JD, Ellmeier W, Littman DR, Stevenson M, Charo IF, Herndier BG, Speck RF, Goldsmith MA: Progress toward a human CD4/CCR5 transgenic rat model for de novo infection by human immunodeficiency virus type I. J Exp Med 2002, 195:719-736.

12. Sawada S, Gowrishankar K, Kitamura R, Suzuki M, Suzuki G, Tahara $S$, Koito A: Disturbed CD4+ $T$ cell homeostasis and in vitro HIV-I susceptibility in transgenic mice expressing $T$ cell linetropic HIV-I receptors. J Exp Med 1998, | 87: | 439-| 449.

13. Cutino-Moguel T, Fassati A: A phenotypic recessive, post-entry block in rabbit cells that results in aberrant trafficking of HIV-I. Traffic 2006, 7:978-992.

14. Tsurutani N, Yasuda J, Yamamoto N, Choi BI, Kadoki M, Iwakura Y: Nuclear Import of the Pre-integration Complex Is Blocked upon Infection by HIV-I in Mouse Cells. J Virol 2006.

15. Wei P, Garber ME, Fang SM, Fischer WH, Jones KA: A novel CDK9associated C-type cyclin interacts directly with HIV-I Tat and mediates its high-affinity, loop-specific binding to TAR RNA. Cell I 998, 92:45|-462.

16. Jones KA, Peterlin BM: Control of RNA initiation and elongation at the HIV-I promoter. Annu Rev Biochem 1994, 63:7 I7-743.
17. Taube R, Fujinaga K, Wimmer J, Barboric M, Peterlin BM: Tat transactivation: a model for the regulation of eukaryotic transcriptional elongation. Virology 1999, 264:245-253.

18. Garber ME, Wei P, KewalRamani VN, Mayall TP, Herrmann CH, Rice $A P$, Littman DR, Jones KA: The interaction between HIV-I Tat and human cyclin $\mathrm{TI}$ requires zinc and a critical cysteine residue that is not conserved in the murine CycTI protein. Genes Dev 1998, I 2:35 I2-3527.

19. Trono $D$, Baltimore $D: \mathbf{A}$ human cell factor is essential for HIVI Rev action. Embo J 1990, 9:4155-4160.

20. Mariani R, Rasala BA, Rutter G, Wiegers K, Brandt SM, Krausslich HG, Landau NR: Mouse-human heterokaryons support efficient human immunodeficiency virus type I assembly. J Virol 200I, 75:3|4|-3|5|.

21. Mariani R, Chen D, Schrofelbauer B, Navarro F, Konig R, Bollman B, Munk C, Nymark-McMahon H, Landau NR: Species-specific exclusion of APOBEC3G from HIV-I virions by Vif. Cell 2003, II 4:2I-3I.

22. Goffinet C, Allespach I, Keppler OT: HIV-susceptible transgenic rats allow rapid preclinical testing of antiviral compounds targeting virus entry or reverse transcription. Proc Natl Acad Sci USA 2007, 104:1015-1020.

23. Albritton LM, Tseng L, Scadden D, Cunningham JM: A putative murine ecotropic retrovirus receptor gene encodes a multiple membrane-spanning protein and confers susceptibility to virus infection. Cell 1989, 57:659-666.

24. Cavrois M, De Noronha C, Greene WC: A sensitive and specific enzyme-based assay detecting HIV-I virion fusion in primary T lymphocytes. Nat Biotechnol 2002, 20: I I5 I-I I 54.

25. Venzke S, Michel N, Allespach I, Fackler OT, Keppler OT: Expression of Nef downregulates CXCR4, the major coreceptor of human immunodeficiency virus, from the surface of target cells and thereby enhances resistance to superinfection. J Virol 2006 in press.

26. Li L, Olvera JM, Yoder KE, Mitchell RS, Butler SL, Lieber M, Martin SL, Bushman FD: Role of the non-homologous DNA end joining pathway in the early steps of retroviral infection. Embo J 200I, 20:3272-328I.

27. Sharkey ME, Teo I, Greenough T, Sharova N, Luzuriaga K, Sullivan JL, Bucy RP, Kostrikis LG, Haase A, Veryard C, Davaro RE, Cheeseman SH, Daly JS, Bova C, Ellison RT, Mady B, Lai KK, Moyle G, Nelson M, Gazzard B, Shaunak S, Stevenson M: Persistence of episomal HIVI infection intermediates in patients on highly active antiretroviral therapy. Nat Med 2000, 6:76-8I.

28. Stevenson M, Haggerty S, Lamonica CA, Meier CM, Welch SK, Wasiak AJ: Integration is not necessary for expression of human immunodeficiency virus type I protein products. I Virol 1990, 64:242I-2425.

29. Wu Y, Marsh JW: Selective transcription and modulation of resting $T$ cell activity by preintegrated HIV DNA. Science 200I, 293:1503-1506.

30. Brussel A, Sonigo P: Analysis of early human immunodeficiency virus type I DNA synthesis by use of a new sensitive assay for quantifying integrated provirus. J Virol 2003, 77:10119-10124.

31. Kim J, Martignetti JA, Shen MR, Brosius J, Deininger P: Rodent BCI RNA gene as a master gene for ID element amplification. Proc Natl Acad Sci USA 1994, 9 I:3607-36I I.

32. Kim J, Deininger PL: Recent amplification of rat ID sequences. I Mol Biol 1996, 26 I:322-327.

33. Leavitt AD, Robles G, Alesandro N, Varmus HE: Human immunodeficiency virus type $I$ integrase mutants retain in vitro integrase activity yet fail to integrate viral DNA efficiently during infection. J Virol 1996, 70:721-728.

34. Bieniasz PD, Grdina TA, Bogerd HP, Cullen BR: Recruitment of a protein complex containing Tat and cyclin TI to TAR governs the species specificity of HIV-I Tat. Embo J 1998, 17:7056-7065.

35. Goffinet C, Keppler OT: Efficient nonviral gene delivery into primary lymphocytes from rats and mice. Faseb J 2006, 20:500-502.

36. Reynolds L, Ullman C, Moore M, Isalan M, West MJ, Clapham P, Klug A, Choo Y: Repression of the HIV-I 5' LTR promoter and inhibition of HIV-I replication by using engineered zinc-finger transcription factors. Proc Natl Acad Sci USA 2003, 100:16 | 5-1620. 
37. Kwak YT, Ivanov D, Guo J, Nee E, Gaynor RB: Role of the human and murine cyclin $T$ proteins in regulating HIV-I tat-activation. J Mol Biol 1999, 288:57-69.

38. Fujinaga K, Taube R, Wimmer J, Cujec TP, Peterlin BM: Interactions between human cyclin $\mathrm{T}$, Tat, and the transactivation response element (TAR) are disrupted by a cysteine to tyrosine substitution found in mouse cyclin T. Proc Natl Acad Sci USA 1999, 96:1285-1290.

39. Jordan $A$, Bisgrove $D$, Verdin E: HIV reproducibly establishes a latent infection after acute infection of $\mathrm{T}$ cells in vitro. Embo J 2003, 22: 1868-1877.

40. Schroder AR, Shinn P, Chen H, Berry C, Ecker JR, Bushman F: HIV$I$ integration in the human genome favors active genes and local hotspots. Cell 2002, I 10:521-529.

4I. Mitchell RS, Beitzel BF, Schroder AR, Shinn P, Chen H, Berry CC, Ecker JR, Bushman FD: Retroviral DNA integration: ASLV, HIV, and MLV show distinct target site preferences. PLoS Biol 2004, 2:E234.

42. $\mathrm{Wu} X, \mathrm{Li} Y$, Crise $B$, Burgess $S M$ : Transcription start regions in the human genome are favored targets for MLV integration. Science 2003, 300:1749-175I.

43. Busschots K, Vercammen J, Emiliani S, Benarous R, Engelborghs $Y$, Christ F, Debyser Z: The interaction of LEDGF/p75 with integrase is lentivirus-specific and promotes DNA binding. J Biol Chem 2005, 280: 1784I-I7847.

44. Ciuffi A, Llano M, Poeschla E, Hoffmann C, Leipzig J, Shinn P, Ecker JR, Bushman F: A role for LEDGF/p75 in targeting HIV DNA integration. Nat Med 2005, I I: 1287-I 289.

45. Liou LY, Herrmann CH, Rice AP: Human immunodeficiency virus type $I$ infection induces cyclin TI expression in macrophages. J Virol 2004, 78:8 I |4-8II9.

46. Rohr O, Marban C, Aunis D, Schaeffer E: Regulation of HIV-I gene transcription: from lymphocytes to microglial cells. J Leukoc Biol 2003, 74:736-749.

47. Venzke S, Keppler OT: The role of macrophages in HIV infection and persistence. Expert Rev Clin Immunol 2006, 2:613-626.

48. Levy JA: Pathogenesis of human immunodeficiency virus infection. Microbiol Rev 1993, 57:183-289.

49. Manz MG: Human-hemato-lymphoid-system mice: opportunities and challenges. Immunity 2007, 26:537-54I.

50. Keppler OT, Allespach I, Schuller L, Fenard D, Greene WC, Fackler OT: Rodent cells support key functions of the human immunodeficiency virus type I pathogenicity factor Nef. J Virol 2005, 79:1655-1665.

5I. He J, Chen Y, Farzan M, Choe H, Ohagen A, Gartner S, Busciglio I, Yang X, Hofmann W, Newman W, Mackay CR, Sodroski J, Gabuzda D: CCR3 and CCR5 are co-receptors for HIV-I infection of microglia. Nature 1997, 385:645-649.

52. Reuter S, Kaumanns P, Buschhorn SB, Dittmar MT: Role of HIV-2 envelope in Lv2-mediated restriction. Virology 2005, 332:347-358.

53. Zufferey R, Donello JE, Trono D, Hope TJ: Woodchuck hepatitis virus posttranscriptional regulatory element enhances expression of transgenes delivered by retroviral vectors. J Virol 1999, 73:2886-2892.

54. Van Maele B, De Rijck J, De Clercq E, Debyser Z: Impact of the central polypurine tract on the kinetics of human immunodeficiency virus type I vector transduction. J Virol 2003, 77:4685-4694.
Publish with Bio Med Central and every scientist can read your work free of charge

"BioMed Central will be the most significant development for disseminating the results of biomedical research in our lifetime. "

Sir Paul Nurse, Cancer Research UK

Your research papers will be:

- available free of charge to the entire biomedical community

- peer reviewed and published immediately upon acceptance

- cited in PubMed and archived on PubMed Central

- yours - you keep the copyright
BioMedcentral 